\title{
Performance Measurement in Construction Research and Development
}

\author{
Research Paper
}

Purpose

The study evaluates the impacts of performance measurement in construction research and development.

\section{Methodology}

Empirical data was gathered from semi-structured interviews from academic members and industrial partners who have got involved in collaborative construction R\&D work. The data was analysed by using content analysis technique and with the aid of NVivo and decision explorer software.

\section{Findings}

The paper identifies number of ways in which PM can influence construction R\&D such as facilitating the selection of the best option for R\&D projects; improving the quality of the research work; identifying and ensuring the contribution of the team members; directing the team members towards predetermined targets; improving the transparency of the work; facilitating inter project comparisons; validating the achievements; improving communication; motivating the team; ensuring proper progress of work; and increasing the satisfaction of the stakeholders. Paper also reveals negative impacts of PM within construction $R \& D$ such as waste of resources when the results of PM are not integrated with the system, inclusion of incorrect performance measures, lack of rigour when formulating performance measures etc.

\section{Originality/ Value}

The paper reveals impacts of PM in construction $R \& D$ activities that will be beneficial when managing collaborative construction $R \& D$ projects.

Key words

Construction industry, Performance measurement, Research and development 


\section{Introduction}

The construction industry is subjected to a number of challenges such as improving the efficiency and effectiveness of the construction processes and materials; addressing the growing concerns of environmental considerations and health and safety issues; complying with sustainable development requirements; and addressing cost, time, quality parameters of construction projects (Department for Business, Enterprise and Regulatory Reform, 2007; DTI, 2007; European construction platform, 2005; Hampson and Brandon, 2004; Fairclough, 2002; Laing, 2001). Among the methods suggested to address the aforementioned challenges, engagement in Research and Development (R\&D) activities is noted as being prominent. In this regard, some seminal work done within the construction industry identifies $R \& D$ as an overarching strategy for the construction industry in addressing its challenges and goals (Barrett 2007; Hampson and Brandon, 2004). Fairclough (2002) suggests that innovation driven by $R \& D$ as the way forward if the society needs to be benefited from a modern, efficient, high quality construction industry. Not limiting the importance within the UK, R\&D is being identified as a key factor which develops the construction industries worldwide (Fox and Skitmore, 2007).

Despite the importance of $R \& D$ activities for the growth of the construction industry, there are a number of issues, which affect its success. A low level of investment can be identified for UK construction R\&D when compared with countries like France, Japan and Scandinavia (Gann, 2000) and when compared with other sectors like manufacturing (Department for Business Enterprise and Regulatory Reform, 2007; Institute of Civil Engineers, 2006; DTI, 2006; DTI, 2005; DTI, 2004; Dulaimi et al, 2002; Fairclough, 2002; Seaden and Manseau, 2001; Laing, 2001; Egan, 1998). One of the main reasons for low investment is improper reporting of $\mathrm{R} \& \mathrm{D}$ expenses (Seaden and Manseau, 2001, p: 186) and inadequate mechanisms to evaluate the successfulness of activities (Lorch, 2000). People question the value of R\&D when clear links between its benefits and the financial commitments are not established. Courtney (1999) argues that R\&D returns should be more calculable by means of establishing certain and visible relationships between the investments and output of construction R\&D activities. Further, when the expectations of the participants of construction $R \& D$ activities are not met, a low level of contribution from industrial partners is evident (Barrett and Barrett, 2003; Print, 1999). Moreover, lack of feedback on the progress and success of R\&D activities and lack of communication between the parties involved (Dulaimi et al, 2002; Print, 1999; CRISP consultancy commission, 1999) have reduced the interest and attraction for contributors to ongoing construction $R \& D$ activities. It is being evident that construction $R \& D$ activities lack effective communication, feedback and validation procedures, and coordination between the parties involved in the process (Gann, 2001; Lorch, 2000).

The aforementioned issues within construction $R \& D$ illustrate a need for effective controlling, monitoring and validating mechanisms to enhance its success. A few decades ago, it was believed that imposing financial constraints could negatively affect the freedom and creativity of R\&D activities (Roussel et al, 1991). However, this has been challenged due to the rising cost and resource constraints involved in 
$R \& D$ activities thus requiring rigorous mechanisms to monitor and control the $R \& D$ inputs towards obtaining successful $R \& D$ outputs. More attention is therefore, paid to ensuring the R\&D outputs are properly aligned with the expected goals, increasing the efficiency and effectiveness of $R \& D$ activities, ensuring the accountability of resources consumed and making clear the contributions from $R \& D$ activities towards the organisational developments.

Performance measurement (PM) has been identified as a valuable means of measuring the efficiency and effectiveness of activities in ensuring the outcome of activities are properly aligned with the expected goals. Accordingly, this study suggests the implementation of Performance Measurement within the construction R\&D projects to obtain their success. Though there are number of studies on PM and R\&D in other disciplines, a paucity of literature is evident within the construction sector creating a gap between the need for PM in construction R\&D and its availability. Therefore, this study aimed at addressing the gap in PM and construction R\&D by evaluating positive and negative impacts of PM towards construction R\&D.

The paper first explores PM in general and the need for PM within R\&D. This is followed by the research method used for the study. Positive and negative impacts of PM towards construction R\&D is analysed and presented next followed by the conclusion of the study.

\section{What is performance measurement?}

PM has been identified as a means of assessing the progress made towards accomplishing the pre-determined goals (The Procurement Executive's Association, 1998). The achievement of pre-determined goals depends on a number of influential factors such as the effective coordination of work and motivation of employees. Kerssens-van Drongelen and Bilderbeek (1999, p: 36) acknowledge this and define $\mathrm{PM}$ as "the acquisition and analysis of information about the actual attainment of company objectives and plans, and about factors that may influence this attainment". Neely (1998) defines PM as the quantification of efficiency and effectiveness of past actions by means of data acquiring, collection, sorting, analysing, interpreting and disseminating. Moullin (2002), Pratt (2005) and Kulatunga et al (207) highlight the importance of including stakeholder satisfaction when defining PM as satisfaction of the stakeholders is one of the primary objective of any organisation or process.

There are a number of positive impacts of PM such as continuous evaluation of work, increasing the accountability, direction and motivation of employees, improving communication and assisting in the implementation of strategy etc. (Franco-Santos et al, 2007; Greiling, 2006; Martinez, 2005; Neely et al, 2002; Magretta and Stone, 2002; The Procurement Executive's Association, 1998). Parker (2000) asserts that PM enables managers to make decisions based on facts rather than on intuition and faith. Due to lack of feedback mechanisms to improve organisations' on going performance and challenges, Longenecker and Fink (2001) note that organisations could leverage lower benefit if PM systems are not in place. Agreeing with this view, Cain (2004) identifies PM as the first stage to any improvement process that benefits the end users as well as the organisations. Further, it has been asserted that PM not only evaluates the efficiency and effectiveness of activities in achieving goals but also evaluates 
other factors that influence such achievements and ultimately satisfy the stakeholders (Kulatunga et al, 2007; Moullin, 2002; Kerssens-van Drongelen and Bilderbeek, 1999; Neely, 1998). PM not always provide positive impacts as noted by some of the previous work. The study of Martinez (2005) revealed that use of complicated and excessive performance measures created negative effects due to the considerable consumption of time, investments and commitment of people. When the cost of introducing and implementing PM exceeds the potential benefits of PM, the need of PM can be challenged (Halachmi, 2002). Furthermore, on some occasions the use of PM applications has limited the freedom of managers due to its rigidity (Martinez, 2005).

\section{Value of performance measurement for research and development}

$\mathrm{R} \& \mathrm{D}$ activities have been identified as a critical determinant of achieving the strategic goals of an organisation (van Rooij, 2008; Herath and Bremser, 2005; Bremser and Barsky, 2004). Thus, it has been recognised that R\&D cannot be treated in isolation, but has to be aligned and linked with the corporate strategy of the organisation (Pearson et al., 2000; Kerssens-van Drongelen and Bilderbeek, 1999; Roberts, 1988; Rogers, 1996; Roussel et al., 1991). With this understanding comes the question of implementing the R\&D activities leading to a better attainment of the organisational goals. This question is reflected in the study carried out by Bremser and Barsky (2004, p: 230) that states "a firm can develop a seemingly brilliant $R \& D$ strategy designed to achieve competitive advantage and grow the firm, but implementing strategy is the management challenge". In this context, PM on R\&D helps to creates links between the organisation's strategy and R\&D by translating the organisation's strategy into performance measures which could, in turn, be linked to R\&D activities. A number of studies have revealed that PM of R\&D plays a vital role by influencing and helping organisations to implement their strategies (Bremser and Barsky, 2004; Pearson et al, 2000; Kerssens-van Drongelen et al, 2000; Kerssens-van Drongelen and Bilderbeek, 1999; Werner and Souder, 1997; Brown and Svenson, 1988). Yawson et al (2006) argue that PM for R\&D activities provide the basis to assess whether the organisation is progressing towards its goals, identifies the strengths and weaknesses, decides on the future actions needed for improvements and provides data to request additional resources hence facilitating the implementation strategies.

Often, attention of management is paid to identifying the contribution from R\&D activities towards a competitive advantage for the organisation (Chiesa and Frattini, 2007; Germeraad, 2003). Concerns of investors and shareholders on R\&D spending have demanded identification of the actual contribution from $R \& D$ investments towards the organisational goals, thus increasing the accountability of the proper usage of R\&D investments (Osawa and Yamasaki, 2005).Therefore, Pearson et al (2000) and Nixon (1998) state that management has been forced to find ways to measure the return on $\mathrm{R} \& \mathrm{D}$ expenditure and to evaluate the performance of such activities. In addition to the identification of utilisation of resources, PM in R\&D could identify the proper resource allocation within organisations (Bremser and Barsky, 2004; Pearson et al., 2000; Kerssen-van Drongelen and Bilderbeek, 1999). Furthermore, PM in R\&D improves communication and coordination of the activities (Bremser and Barsky, 2004; Loch and Tapper, 2002). Research carried out in various 
industries indicates that long-term competitive advantage highly depends on commitment to on going R\&D work and the use of PM applications to evaluate its success (Osawa and Yamasaki, 2005; Pearson et al, 2000; Kerssens-van Drongelen et al, 2000; Kerssens-van Drongelen and Bilderbeek, 1999; Werner and Souder, 1997; Tipping et al, 1995; Brown and Svenson, 1988).

As discussed above, the benefits of PM in $R \& D$ is being well explored. However, a paucity of literature is evident for PM applications within construction R\&D and impact of PM applications within construction $R \& D$ is yet to be investigated. Accordingly, this study evaluates the influences of PM towards construction R\&D. The section below discusses the research methodology adopted to address the objectives of this study.

\section{Methodology}

Construction $R \& D$ activities can take the form of pure academic research, pure industrial research or collaborative research between academia and industry. Collaborative research work has a number of benefits over the other two methods as they merge the experience, knowledge and expectations of the industrial practitioners and academia. As a result, the outcome of collaborative $R \& D$ is more applicable to industry, is easily understood and has greater possibility of adoption (Gilkinson and Barrett, 2004). Accordingly, collaborative construction R\&D activities were taken as the boundary of the study whilst data was gathered from the academics and industrial partners who have got involved in collaborative research projects. The details of the respondents are given in Table I.

To uncover the insight related to the influences of PM within collaborative construction $\mathrm{R} \& \mathrm{D}$ work, the study required a data collection method that facilitates in-depth inquiry. As noted by Silverman (2001, p: 87) the interviews in social science strive “...to generate data which give an authentic insight into people's experience". Accordingly, a series of semi-structured interviews were carried out to collect primary data on the impacts of PM on collaborative construction R\&D activities. The use of semi- structured interviews helped the researcher to gather the data in a flexible and conversational manner but with a focus towards the study. As stated by Yin (2003), for the data collection to be effective, precise communication to the participants is needed regarding the purpose of the study. Thus, a study brief explaining the overall objectives, benefits to the respondents, commitment from the respondents and how confidentiality would be dealt with during the interviews was given to the interviewees. The interview guidelines were piloted and revised prior to distribution among the respondents. Saunders et al (2007) assert that the preliminary analysis of the pilot test data is important as it ensures the researcher acquires the required answers. Therefore, the responses from the pilot interviews were analysed to check whether the interviews generates the required data to satisfy the research questions of the study. With the consent of the interviewees, the interviews were recorded using a digital voice recorder. The duration of the interviews was in the range of $60-90$ minutes.

Insert Table I 
The first section of the interview was on the background details of the interviewees. Accordingly, the interviewees were asked about their involvements, tasks and responsibilities within collaborative construction $R \& D$ activities. The second section of the interview was manly targeted on capturing positive and negative impacts of PM towards collaborative construction R\&D. After carrying out the interviews, they were transcribed and sent back to the interviewees for confirmation.

For the analysis of the semi-structured interviews, content analysis was used. Content analysis is a data analysing techniques for collecting and organising non-structured information into a standardised format, which helps to make inferences about the characteristics and meaning of written or recorded material (The Bureau of Justice Assistance, 2006). The content analysis was carried out by using NVivo software. To perform the analysis, the interview transcripts were uploaded to the NVivo software and carefully scrutinised with the aim of identifying concepts/answers related to the research questions of the study. A sample of the NVivo structure is presented in Figure 1. After identifying the main concepts/answers related to the research question through NVivo software, they were imported to decision explorer software to create cognitive maps as shown in Figure 2, Figure 3, Figure 4 and Figure 5. The decision explorer software was used to link the main concepts/answers of the research questions with their supportive evidence extracted from the interview transcripts. In Figure 2 to 5 main concepts/answers of the research questions are shown within rectangles whilst the supporting evidence is shown with arrows connected to the rectangles. The numbers indicated in the diagrams are random numbers and do not have any relevance to the results.

The following section details out the main findings of the study.

\section{Findings}

The study revealed a number of positive and negative impacts of PM within collaborative construction R\&D activities. Table II provides the summary of the results obtained from the empirical investigation of the study.

\section{Insert Table II}

The above results are discussed in detail in the below section. Comparison of results obtained from the empirical investigation of this study with literature review also carried out in the below section.

\section{Positive impacts of performance measurement}

The study revealed the importance of continuous monitoring and controlling (concept 14 and 15 in Figure 2; concept 31 and 34 in Figure 3) of collaborative construction R\&D projects. It was identified that PM helps to monitor the R\&D activities and keep the team focused on the targets that they need to achieve. When the performance measures are in place, achieving them shows that the project objectives are fulfilled and the project is moving forward as expected. As stated by one of the researchers "it (PM) helps extensively to keep your research focused, without that your research can go all over. So by having performance measures ... you know that at the end of the day you are achieving your aims and objectives". Furthermore, failure to achieve the 
set targets/ performance measure indicates the lagging areas within the R\&D project. Identifying lagging areas could direct the project team to take corrective measures such as allocation of additional resources, or even to re-base/ re-plan the set targets based on current performance. Taking corrective measures promptly ensures that the R\&D project would not arrive at a situation where it is impossible to retrieve the situation. Thus, continuous monitoring and controlling by PM ensures the smooth flow of work and that the output is aligned within the set aim and objectives of the project. This increases stakeholder satisfaction by indicating their requirements and expectations are properly addressed, and getting the value for money and commitment, that they are investing in. Similar to the findings of the empirical investigation of this study, Cain (2004) identifies PM as the first stage to any improvement process that benefits the end users as well as the organisations.

It was identified from literature that funding bodies and industrial partners are reluctant to invest and contribute to construction $R \& D$ activities as a result of non achievement of expected targets (see Barrett and Barrett, 2003; Seaden and Mnseau, 2001; Gann, 2000; Print, 1999; Hodkinson, 1999). Thus, utilisation of PM within construction R\&D projects would minimise such issues. Therefore, with the aid of PM, the expected targets could be achieved which could provide reassurance for the funding bodies to provide continued funding for future projects. Furthermore, the satisfaction of industrial partners' requirements would create long-term research partnerships and provide effective contributions throughout the $R \& D$ project leading to production of results with more applicability.

As part of the monitoring and controlling process, the study revealed that PM helps to report on the success of achieving the targets, analyse any lagging areas and reveal the utilisation of resources. Seaden and Mnseau (2001) and Hodkinson (1999) asserted that due to improper reporting mechanisms, the parties involved within R\&D projects do not have a clear understanding of its status thus, the importance of creating clear and visible links between the R\&D spending and their impact was highlighted. Kerssens-van Drongelen et al (2000) indicated that the accountability of R\&D investments has increased due to the interest of investors and shareholders on knowing the utilisation of $R \& D$ resources. Therefore, as discussed above, PM would improve the reporting structure of $R \& D$ projects and would show how $R \& D$ investment is used hence, enhancing the success of $R \& D$ activities.

\section{Take in Figure 2}

Moreover, PM was claimed by the respondents as a milestone for the reflection of activities. As part of monitoring and control, PM helps to reflect on the achievement of targets, their success or failure, whether there would have been alternative ways of achieving those targets and how those targets have contributed to the overall success of the project (concept 17 in Figure 2). Such reflections are important in further improving the current $R \& D$ project and can be used to make improvements for other R\&D projects (concept 11 in Figure 2). Thus, PM leads to continuous improvement of $R \& D$ projects. In addition, the study revealed that PM helps to identify the contributions of team members (concept 16 in Figure 2). Accordingly, one of the principal investigators commented "You can measure the inputs of different contributors and ....at least you can get an indication about whether all the parties are 
contributing in the quantity of contribution as expected". Identification of the contribution of different parties leads to another benefit of PM; that of improving the transparency of the work (concept 18 in Figure 2). In a R\&D project, there can be partners from different locations even from different countries. Within that scenario, PM improves the transparency of the work by demonstrating the utilisation of resources and showing the contribution of parties towards the success of the project. Similar to these findings, Greiling (2006) also argues that PM can be used as a tool to show the accountability of the parties involved in.

\section{Take in Figure 3}

When performance measures are put in place with their time lines, team members can concentrate on those and plan the work accordingly thus directing team members (concept 12 in Figure 2) towards achieving the targets within their given time frame. It was revealed that having short term targets was a successful way of achieving the overall objectives of the project. Accordingly, one of the principal investigators stated "... having performance measures means, you are dividing the objectives into achievable, short term targets and giving them time scales". Further, the interviewees identified PM as a motivator (concept 13 in Figure 2 and concept 32 in Figure 3) for the project team since the achievement of the performance measures indicates the project is progressing smoothly. Hence, one of the industrial partners commented "PM gives you the moral support especially, when the performance is good...it (PM) motivates you and can be a source of bringing the people together". Franco-Santos et al (2007) and Greiling (2006) also identify PM as a motivation tool for the employees to achieve targets set out by the organisation.

In addition to this, PM acts as a "quality controller" (concept 30 in Figure 3) by ensuring the R\&D project accomplishes the expected standards. When the quality parameters are set out within the performance measures, achieving those measures shows that the project is well within the required standards. Also, PM helps to validate the findings (concept 33 in Figure 3) of the project through peer reviews, publications, citations and demonstrates that the results of $R \& D$ work are acknowledged and appreciated by the wider community. Moreover, the study revealed that PM aids the improvement of communication within the R\&D project (concept 10 in Figure 2). Through the performance measures, the project team is aware of the overall objectives of the project. Further, due to the PM, the project team are familiar with the progress of the $R \& D$ project: whether the project is heading towards its objectives or not. A number of studies carried out in other disciplines also highlighted the influence of PM on improving communication of strategy, priority factors of organisations (Franco-Santos et al, 2007; Martinez, 2005; Neely et al, 2002; Magretta and Stone, 2002; The Procurement Executive's Association, 1998).

Having discussed the positive impacts of PM in collaborative construction R\&D, the section below looks in to the negative impacts identified from the study.

\section{Negative impacts of performance measurement}

Besides the benefits of PM, a number of negative impacts were also revealed. It was found out that if the results of PM do not become part of the R\&D project, the process of PM will not add value to the R\&D project (concept 22 in Figure 4; concept 42 in 
Figure 5). This demonstrates the need for providing feedback from the PM results to the R\&D project thus, making PM an integral part of the R\&D project. Further, the time and other resources consumed for PM could be used elsewhere to achieve the objectives of the project. As stated by one of the principal investigators "You can waste lots of resource of the project measuring what's happening and rather than trying appropriate methods, practices within the project. This can distract you from what you should be doing". This highlights the need for developing efficient and effective performance measures which would not consume extensive time and manpower. The literature also indicated that the existence of a large number of performance measures could create problems in time and resource consumption and create difficulties in integrating them within the organisational performance making the implementation of PM complicated (Cooper and Kleinschmidt, 2007).

\section{Take in Figure 4}

In addition to this, setting incorrect targets as performance measures (concept 200 in Figure 4; concept 430 in Figure 5) could result in the wrong information being feed into the system. Accordingly, one of the researchers commented "...if the performance criteria are one dimensional, it will capture only that. But it will also lose the other things". Hence, when selecting the performance measures, it is important to consider the requirements and expectations of the project and parties involved in the project. Martinez (2005) also experienced similar results in her study and revealed that the use of complicated and excessive performance measures created negative effects due to the considerable consumption of time, investments and commitment of people. The study further identified that incorrect timing of PM could result in adding incorrect feedback to the system. Therefore, in addition to the selection of efficient and effective performance measures, the correct timing of measurement must be emphasised for PM to be successful. Where good performance motivates team members, poor performance could de-motivate the project team (concept 41 in Figure 5). Accordingly, one of the industrial partners "they (PM) can identify poor delivery, which can lead to moral issues, frustration and the performance can be damaged thereafter". To avoid such frustrations and negative impacts on the projects, PM results needs to be utilised wisely in identifying the strengths and weaknesses of the current practices and take on board to improve the future performance of $R \& D$ practices rather avoiding PM as a whole. Another negative aspect that could affect the effectiveness of PM applications was revealed as lack rigour and good background knowledge when formulating the norms of performance measures (concept 201 in Figure 4). Therefore, the formulation of performance measures based on previous knowledge and experience can be emphasised.

\section{Take in Figure 5}

As discussed above, the study revealed number of positive and negative impacts of PM on collaborative construction R\&D activities. Even though there are negative impacts of PM, the authors argue that the solution is not to avoid the use of PM as a whole, but to design and develop PM applications which are user friendly and which negates the negative impacts by providing more positive impacts. 


\section{Conclusion}

It has been identified that the cause of a majority of the issues in construction R\&D is directly or indirectly rooted with the lack of evaluation mechanisms implying the need for PM. Within this background, this study explored the impact of PM on the collaborative construction R\&D activities. The study revealed both positive and negative impacts for PM in construction R\&D. Positive impacts include facilitating the selection of the best option/ aim and objectives for R\&D projects; improving the quality of the research work; identifying and ensuring the contribution of the team members; directing the team members towards predetermined targets; improving the transparency of the work; facilitating inter project comparisons; validating the achievements; improving communication; motivating the team; ensuring proper progress of work; and increasing the satisfaction of the stakeholders. Thus, it can be seen that PM positively influences the collaborative construction $R \& D$ project from its initiation to dissemination of the project results and also for the proper management of the R\&D work. The negative impacts of PM on the construction R\&D projects suggest the importance of making PM an integral part of the R\&D project so that it acts as a feedback loop to the system. Further, the selection of efficient and effective performance measure, correct timing of performance reviews and selection of performance measures based on previous knowledge and experience was also considered essential. Most significantly, the importance of choosing the correct target/ performance measures was highlighted though the negative impacts derived from this study.

Even though there are numbers of studies carried out in other disciplines to identify the impacts of $P M$ in $R \& D$, lack of studies are evident within construction $R \& D$. Hence, this study contributes to the knowledge by identifying positive and negative impacts of PM on collaborative construction $R \& D$. The study argues that even though there are negative impacts of PM in construction $R \& D$, they can be minimised when performance measures are developed with proper background and by making PM a part of the construction R\&D management system. Based on the emphasis got from the study on choosing the correct targets and performance measures for effective PM in construction R\&D activities, the study suggests PM based on critical success factors as the way forward, as PM based on critical success factors could ensure proper implementation and management of success factors of construction $R \& D$ activities. Accordingly, development of performance measures based on critical success factors of construction R\&D can be suggested as future research.

\section{References}

Barrett, P. 2007, Revaluing Construction: a holistic model, Building Research and Information, Vol. 35(3), pp. 268-286

Barrett, S. P., and Barrett, L. C. 2003, Research as a kaleidoscope on practice, Construction management and economics, Vol. 21(7), pp. 755-766

Bremser W. G., and Brasky, N. P. 2004, Utilising the balanced score card, $R \& D$ management, Vol. 34(3), pp. 229-238 
Brown, M. G., and Svenson, R. A. 1988, Measuring R\&D productivity, Research Technology management, Vol. 41(6), pp. 30-35

Cain, C. T. 2004, Performance measurement for construction profitability, Blackwell publishing Ltd., Oxford

Chiesa V., and Frattini F. 2007, How do measurement objectives influence the R\&D performance measurement system design?, Management Research News, Vol. 30(3), pp. $187-202$

Cohen, W. M., and Levinthal, D.A. 1989, Innovation and learning: the two faces of R\&D, The Economic Journal, Vol. 99(397), pp. 569-596

Cohen, W. M., and Levinthal, D.A. 1990, Absorptive capacity: a new perspective on learning and innovation, Administrative Science Quarterly, Vol. 35(1), pp. 128-52

Cooper, R.G., and Kleinschmidt, E.J. 2007, Winning businesses in product development: the critical success factors, Research Technology Management, Vol. 50 (3), pp. 52-66

Courtney, R. G. 1999, Innovative ways of funding construction Research: an ideas paper, Construction research and innovation strategy panel, (accessed $21^{\text {st }}$ June 2005), available from: http://ncrisp.steel-sci.org/Publications/9913fpRC.pdf

CRISP consultancy commission, 1999, Linking construction research and innovation to research and innovation in other sectors, Construction research and innovation strategy panel (accessed $15^{\text {th }}$ December 2005), available from: http://ncrisp.steelsci.org/Publications/ws984_r.pdf

Department for Business, Enterprise \& Regulatory Reform, 2007, Draft Strategy for Sustainable Construction, A consultation paper, (accessed: Feb 2008), http://www.berr.gov.uk/files/file40641.pdf

Department of Trade and industry (DTI), 2004, Construction Research Programme Annual Report 2003/4, DTI, (accessed $11^{\text {th }}$ June 2005), available from:

http://www.dti.gov.uk/construction/research/2004chapterone.htm\#Innovation\%20Revie $\underline{\mathrm{wS}}$

Department of trade and industry, 2005, The R\&D scoreboard 2005, DTI, UK

Department of trade and industry, 2006, The $R \& D$ scoreboard 2006, DTI, UK

DTI, 2007, The construction programme: project showcase, (accessed: Feb 2007), available from: http://www.berr.gov.uk/files/file37735.pdf

Dulaimi, M F., Ling, F.Y.Y., Ofori, G., and De Silva, N. 2002, Enhancing integration and innovation in construction, Building research and information, Vol. 30(4), pp. 237-247 
Egan, J. 1998, Rethinking construction: Report from the construction task force, Department of the environment, transport and regions, UK

European construction platform, 2005, Strategic research agenda for the European construction sector-achieving a sustainable and competitive construction sector 2030, Draft version, (accessed: $10^{\text {th }}$ August 2005), available from:

http://www.ectp.org

Fairclough, J., 2002, Rethinking construction innovation and research: A review of government $R$ and $D$ policies and practices, Department of Trade and Industry, London

Fox, P., and Skitmore, M. 2007, Factors facilitating construction industry development, Building Research and Information, Vol. 35(2), pp. 178-188

Franco-Santos, M., Kennerley, M., Micheli, P., Martinez, V., Mason, S., Marr, B., Gray, D., and Neely, A. 2007, Towards a definition of a business performance measurement system, International Journal of Operations \& Production Management, Vol. 27(8), pp. 784-801

Gann, D. M. 2000, Building innovation, Thomas Telford, London

Gann, D. M. 2001, Putting academic ideas into practice: technological progress and the absorptive capacity of construction organisations, Construction management and economics, 19.3, 321-330

Germeraad, P. 2003, Measuring R\&D in 2003, Research Technology Management, Vol. 46(6), pp. 47-56

Gilkinson, N., and Barrett, P. 2004, The unanticipated impacts of research on practice, CIB world congress, $2^{\text {nd }}-7^{\text {th }}$ May, Canada

Greiling, D. 2006, Performance measurement: a remedy for increasing the efficiency of public services?, International Journal of Productivity and Performance Management, Vol. 55(6), pp. 448-465

Hampson, K., and Brandon, P. 2004, Construction 2020: A vision for Australia's property and construction industry, CRC Construction innovation, Australia

Halachmi, A., 2002, Performance measurement: a look at some possible dysfunctions, Work Study, Vol. 51(5), pp. 230-239

Herath H. S. B., and Bremser, W. G. 2005, Real option valuation of research and development investments, Managerial auditing journal, Vol. 20(1), pp. 55-72

Hodkinson, R. 1999, Innovative ways of funding construction Research: an ideas paper, Construction research and innovation strategy panel, (accessed $21^{\text {st }}$ June 2005), available from: http://ncrisp.steel-sci.org/Publications/9913fpRC.pdf 
Institute of Civil Engineers, 2006, Infrastructure research priority, (accessed: March 2007), available from:

http://www.ncrisp.org.uk/Publications/Infrastructure\%20Research\%20Priorities.pdf

Kerssens-van Drongelen, I. C., and Bilderbeek, J. 1999, R\&D performance measurement: more than choosing a set of metrics, $R \& D$ Management, Vol. 29(1), pp. $35-46$

Kerssens-van Drongelen, I., Nixon, B., and Pearson, A., 2000, Performance measurement in industrial R\&D, International Journal of Management Review, Vol.2(2), pp. 111-143

Kulatunga, U, Amaratunga, D, and Haigh, R 2007, Performance measurement in construction research and development, International Journal of Productivity \& Performance Management, Vol. 56. No. 8, pp. 673 - 688

Laing, M. 2001, Yesterday, today and tomorrow - lessons from the past we can take forward into the future, Reading construction forum, Oxford

Lim, J. N., and Ofori, G. 2007, Classification of innovation for strategic decision making in construction businesses, Construction Management and Economics, Vol. 25(9), pp. $963-978$

Longenecker, C.O., and Fink, L.S. 2001, Improving management performance in rapidly changing organisations, Journal of Management Development, Vol. 20(1), pp. $7-18$

Lorch, R. 2000, Improving the communication of academic research to the construction industry, Construction research and innovation strategy panel, (accessed $20^{\text {th }}$ February 2006), available online from: http://ncrisp.steelsci.org/Publications/9916frLo.pdf

Loch, C. H., and Tapper, U. A. S. 2000, R\&D performance measurement that are linked to strategy, working paper, INSEAD, (accessed $5^{\text {th }}$ March 2005), available from: http://ged.insead.edu/fichiersti/inseadwp2000/2000-14.pdf

Magretta, J., and Stone, N. 2002, What management is: How it works and why its everyone's business, Free press, New York

Martinez, V. 2005, Performance measurement Systems: Mix Effects, (accessed $15^{\text {th }}$ August 2005), available from: http://euram2005.wi.tum.de/index.php/

Moullin, M. 2002, Delivering Excellence in Health and Social Care, Open University Press, Buckingham

Neely, A. 1998, Measuring Business performance, Economist books, London

Neely, A., Adams, C., and Kennerley, M. 2002, The performance prism: the scorecard for measuring and managing business success, Prentice Hall, London 
Nixon, B. 1998, Research and development performance measurement: a case study, Management accounting research, Vol. 9(3), pp. 329-355

Osawa, Y., and Yamasaki, Y. 2005, Proposal of industrial research and development performance indices, $R \& D$ management, Vol. 35(4), pp. 455-461

Parker, C. 2000, Performance Measurement, Work study, Vol. 49(2), pp. 63-66

Pearson, A. W., Nixon, W. A., and Kerssens-van Drongelen, I. C. 2000, R\& D as a business - what are the implications for performance measurement?, $R \& D$ Management, Vol. 30(4), pp. 355-366

Pratt, D. 2005, A comment on the debate between Max Moullin and Fabrizio Bocci, Perspective on performance, Vol. 4(2), pp. 17-19

Print, M, 1999, Funding Construction Industry Research and Innovation - time for a change?, (accessed 15 ${ }^{\text {th }}$ June 2005), Constructions research and innovation strategy panel, UK, available form: http://www.ncrisp.org.uk/Articles/News_Home.asp

Roberts, E. B. 1988, What we've learned managing invention and innovation, Research Technology Management, Vol. 31(1), pp. 11-29

Rogers, D. M. A. 1996, The challenge of fifth generation R\&D, Research technology management, Vol. 39(4), pp. 33-41

Roussel, P. A., Saad, K. N., and Erickson, T. J., 1991, Third Generation R\&D: Managing the Link to Corporate Strategy, Harvard Business School Press, Boston, MA

Saunders, M., Lewis, P. and Thornhill, A. 2007, Research methods for business students, 4th edition, Pearson Education Ltd., Harlow.

Seaden, G. 2002, Changing more than R\&D: responding to the Fairclough Review, Building Research and Information, Vol. 30(5), pp. 312-315

Seaden, G., and Manseau, A. 2001, Public policy and construction innovation, Building research and information, Vol. 29(3), pp. 182-196

Silverman, D. (2001), Interpreting qualitative data: Methods for analysing talk, text and interactions, $2^{\text {nd }}$ edition, SAGE publications, London

Tipping, J.W., Zeffren, E., and Fusfeld, A.R. 1995, Assessing the value of your technology, Research Technology Management, Vol. 38(5), pp. 22-39

The Bureau of Justice Assistance, 2006, Content Analysis - definition (accessed 14 January 2008), available from:

http://www.ojp.usdoj.gov/BJA/evaluation/glossary/glossary_c.htm

The Procurement executives' association, 1998, Guide to a Balanced Scorecard performance management methodology, (accessed $21^{\text {st }}$ January 2005), available from: 
http://professionals.pr.doe.gov/ma5/MA5Web.nsf/d152596b6fe7366485256a5d005a22 59/7363e1ab1e5a429a85256ae80042cb6d/\$FILE/BalancedScorecardPerfAndMeth.pdf

Van Rooij, A. 2008, How R\&D helped transform DSM, Research Technology Management, Vol. 51(1), pp. 43-48

Werner, B. M., and Souder, W. E. 1997, Measuring R\& D performance: state of the art, Research-Technology Management, Vol. 40(2), pp. 34-42.

Yawson, R. M., Amoa-Awua, W. K., Sutherland, A. J., Smith, D. R., and Noamesi, S. K. 2006, Developing a performance measurement framework to enhance the impact orientation of the Food Research Institute Ghana, $R \& D$ Management, Vol. 36(2), pp. $161-172$

Yin, K. 2003, Case study research: Design and methods, $3^{\text {rd }}$ edition, SAGE publications, London 